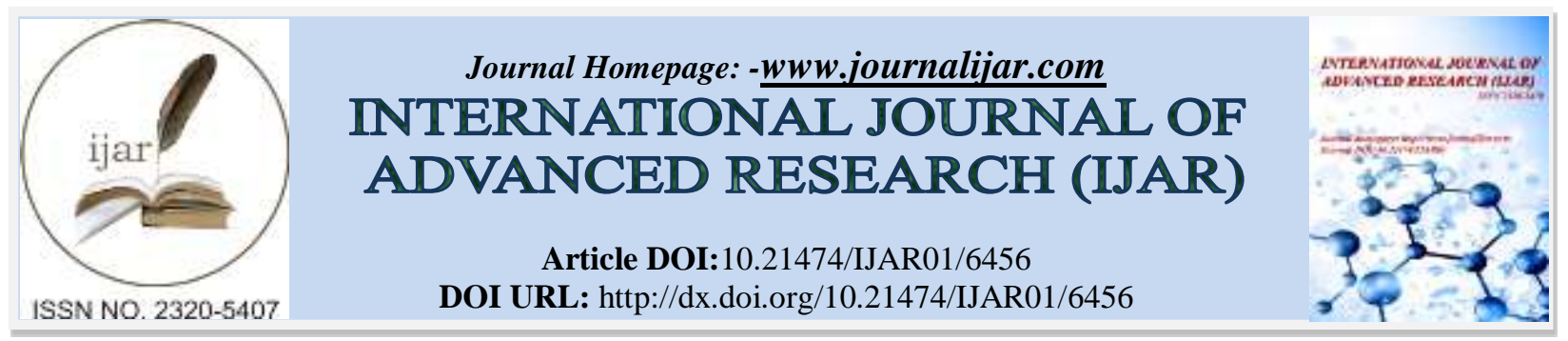

RESEARCH ARTICLE

\title{
ADJUSTMENT DISORDER AMONG MEDICAL STUDENTS IN ARABIAN GULF UNIVERSITY BAHRAIN, A CROSS-SECTIONAL, DESCRIPTIVE STUDY.
}

\author{
Dr. Bader Alnakhli, Dr. Ahmed Al-Mahrezi, Dr. Fatimah Al Radhi, Dr. Ammar Mohammad, Dr. Abdulelah \\ Bohulaygah, Dr. Fatimah Alzoori, Dr. salman alaliwi and Dr. Musaad Al Hurayis. \\ Arabian Gulf University, Road 2904, Building 293, Manama 329, Bahrain.
}

\section{Manuscript Info}

Manuscript History

Received: 06 December 2017

Final Accepted: 08 January 2018

Published: February 2018

Keywords:-

Adjustment Disorder; Medical Students.

\begin{abstract}
Being a Medical student is known to be a stressful period. And failure to cope with stress may lead to different psychiatric illness. Among which is adjustment disorder. A cross-sectional, descriptive study was conducted at an undergraduate medical school with a seven-year curriculum, in Bahrain. Approximately twenty Medical students were included from each year of all seven years. Total number of students who completed the questioner (135). Aiming to measure the prevalence and severity of adjustment disorder (AD) among medical students. The study was conducted using Kessler Psychological Distress Scale (K10), which is used to assess the extent of stress. The results showed that $65.9 \%$ (89) of the students included are free from adjustment disorders and $34.1 \%$ (46) are having potential adjustment disorder. Of those who have potential adjustment disorder was found to be almost equal between male and female.
\end{abstract}

Copy Right, IJAR, 2018,. All rights reserved.

\section{Introduction:-}

Adjustment disorder is characterized by a maladaptive reaction to an identifiable stressor, such as loss of job, divorce, or failure in school. It is also a state of subjective distress and emotional disturbance, which arises during the course of adapting to stresses of significant life changes, stressful life events, serious physical illness, or possibility of serious illness Symptoms of adjustment disorder usually occur within 3 months of the stressor and must remit within 6 months after the stressor is gone. Stress is ubiquitous and a person learns to deal with stress over time. However, when coping mechanisms fail to ameliorate stress effectively, adjustment disorder is precipitated. The symptoms may include anxiety, depression, or disturbance of conduct. They usually are severe enough to cause impairment in function. Adjustment disorders are divided into subgroups based on the dominant symptoms of anxiety, depression or behavior ${ }^{(1)}$. Being a Medical student could be a risk factor to have a psychiatric illness. According to studies Medical students experience high levels of distress, including burnout, depression, and suicidal ideation ${ }^{(2,3)}$. Dealing and facing many stressors in their academic years, medical students have to choose and create coping mechanisms to deal with stressors. Stressors can vary between long hours of study, fewer vacations, being humiliated and mistreated by consultants, lack of support from medical school authorities and dealing with terminally ill patients ${ }^{(4)}$. A study was done In Peru have showed that medical students had the highest stress level among students of different fields, it also showed that focusing on the problem, positive re-evaluation and social support were the most coping strategies used by them ${ }^{(5)}$. Courses and the status of achievement, uncertainties about future and economic problems were the most stress situations that faced medical students in Turkey. Talking with the related person, studying more and thinking then making plans for solutions were the most effective coping ways 
with these stresses ${ }^{(6)}$. The general prevalence of common mental disorder was $40 \%$ in medical students ${ }^{(7)}$. The prevalence and risk varied between students who are active in their clinical years and between those who are still in the pre-clinical years, common mental disorders were higher among clinically not yet active than among clinically active students ${ }^{(8)}$. Female Medical student were 18.7 higher of being stressed over males based on a study in King Saud University, $\mathrm{KSA}^{(9)}$. Medical student begin with premedical year, students at this level were at higher stress because of the undeveloped coping skills ${ }^{(10)}$. Medical students in general have to read a condense materials, and most of this important material is in 3rd and 4th year so students at this periods were found to be more anxious ${ }^{(11)}$ Medical student transition from basic science to clinical years was yet another factor that contributed to their stress. Other study found that first clinical year (year5) Students were more stressed than the second clinical year (year6) ${ }^{(12)}$. Medical students with positive family history of mood disorder had a higher chance of developing Mental illness ${ }^{(13)}$. Medical students who pay to their institute were at higher stress than others because they could have some financial issues that contributed to their stress ${ }^{(14)}$. One of the good coping strategies is seeking social support like family or friends ${ }^{(15)}$. Somehow weather changes, homesickness, lack of contact with family, pressure of studies, bullying and cadaveric dissection were all identified as environmental factors associated with stress among medical student in a study that was conducted at medical college in Islamabad, Pakistan ${ }^{(16)}$. In a study that was made in Casablanca Medical Faculty, Morocco, in total of 275 medical students the overall finding showed that approximately $52 \%$ of the students were stressed by examinations, and the fifth year medical students showed the highest stress prevalence with no difference between female and male students ${ }^{(17)}$. In Libya a study was done and suggested that stress management and relaxation programs must be offered on campus to prevent stress-related symptoms. However, although it is important to help students cope with stresses, interventions by universities aimed at reducing the impact of academic stressors on students may also be of great importance ${ }^{(18)}$. Emotional resilience skills training embedded into the medical school curriculum could reduce psychological distress among medical students ${ }^{(19)}$. Based on a cross-sectional self-reported survey, medical students perceive that exams are the most common source of chronic stress for young people entering adulthood. The level of perceived stress among medical school students is high. However, graduating students cope better with stress than students starting the education, indicating that one can learn to fight stress and also the suicidal thinking decreases. This makes it possible to minimize the negative health effects of chronic stress ${ }^{(20)}$. The students who are most vulnerable are those with fewer social networks, and those who are recent immigrants ${ }^{(21)}$. A higher prevalence of anxiety symptoms was found in first-year medical students as compared with sixth-year students. Strategies should be developed to help medical students, particularly female students, manage these symptoms at the beginning of their medical training ${ }^{(22)}$.

\section{Research aim and objectives:-}

To estimate the prevalence of adjustment disorders among medical student; to explore whether there are differences between men and women. Early screening to prevent severe complications and possible progression to severe psychiatric illnesses that would directly affect their occupational performance and function. To provide awareness programs e.g. more counseling, videos and provide coping skills workshops.

\section{Methods:-}

This research is a cross-sectional study to assess the prevalence and severity of adjustment disorder among a sample of medical students attending the Arabian Gulf University using a questionnaire tool literature. Differences in symptoms presentation between foundation years, premedical sciences phase (Year 1), basic sciences phase (year 2 4) and clinical clerkship phase (Year 5 \& 6) will be addressed in this study.

\section{Study Site:-}

The study took place in the College of Medicine and Medical Sciences, Arabian Gulf University, Bahrain. The questionnaire contains short basic socio-demographic data, Kessler 10-Item Questions (K10) and 5 other questions to learn about persistence and impairment ${ }^{(23)}$.

K10 is a self-administered questionnaire intended to gain global measures about depression and anxiety symptoms that the person has experienced in the past 4 weeks. K10 was developed by Kessler and Mroczek and supported from the U.S. government's National Center for Health Statistics. Historically Kessler and Mroczek reviewed 5000 items from different resources and they came to 45 items. These 45 items have passed through different surveys; in 1992, a USA mail survey and in 1993 telephone survey then eventually they have become 10-6 items which were sensitive enough to measure the threshold for identifying serious from non-serious mental illness ${ }^{(24,25)}$. The K10 consists of 10 questions in the form of "how often in the past month did you feel..." and offers specific symptoms, such as 'tired out for no good reason', 'nervous', and 'sad or depressed'. The five possible responses for each 
question range from 'none of the time' to 'all of the time' and were scored from 1 to 5 respectively. All the questions were collated to obtain a total score. The total score was interpreted as follows: a score of less than 20 was considered not to represent stress of any level while a score of 20-24 represented mild stress, 25-29 represented moderate stress, and 30-50 represented severe stress ${ }^{(26)}$. The K10 questionnaire was observed to have good psychometric properties with a Cronbach's alpha of 0.89 [95\% confidence interval (CI) $0.88-0.90]$.

\section{The Inclusion Criteria:-}

1. Medical student in the Arabian Gulf University.

2. Both male and female students are included.

3. Students from all years.

4. Willing to participate in the study.

\section{The Exclusion Criteria:-}

1. Students with medical conditions.

2. Students with psychiatric condition.

3. Incomplete surveys.

\section{Sample Size:-}

The study was powered up using a sample of 160 convenient students. Sample size was calculated using an alpha of 0.05 and $80 \%$ power indicated that a minimum of 140 subjects to determine a difference in the prevalence proportion of at least $20 \%$ as an effect size for adjustment disorder.

\section{Data Analysis:-}

The data was analyzed using an IBM SPSS statistics version 23.

\section{Confidentiality of Data:-}

The data that was collected for the study was destroyed after the analysis.

\section{Ethical Approval:-}

Research approval sought from the Research Committee, Arabian Gulf University, in Kingdom of Bahrain. Participation was absolutely voluntary. No names, identification numbers or addresses were taken during the data collection to preserve anonymity and confidentiality.

\section{Results:-}

The data were collected from 135 medical students distributed randomly and accidentally equal between males and females. We targeted approximately 20 student randomly from 7 academic years $.92 .6 \%$ of the candidate were singles and $7.4 \%$ were married their stay were distributed almost equally between university hostel, private apartment and family house. Most of them have a scholarship (Table 1)

$65.9 \%$ of the student are free from adjustment disorders and 34.1 are having potential adjustment disorders $37.8 \%$ of those with potential adjustment disorders are likely to be well. The student's percentage with potential adjustment disorders is declined in term of severity as it becomes more severe (Table 2)

The likelihood of having adjustment disorder is found to be almost equal between males and females, more in those in basic science years than those in clinical years most probably due to the higher number of student in basic science years, more in the older student, and almost equal between the nationalities (Table 3).

\section{Discussion:-}

Medical school is the foundation of the new doctors and the place where all the great doctors and the health providers were born in, so as a medical faculty staff and members work to provide the best environment for their students, and make them feel more comfortable and more affective in their upcoming years. Psychological evaluation of the students is mandatory so we have good and effective health providers in the future. So we saw that it's important to know if the students are facing psychological issues from the stressors that they face every single day as a medical student in AGU. We found that According to the result of our study that female students had more potential than male students to develop adjustment disorder and that actually goes with the study published in KSA 
that female were having more stress related mental issues during their medical life because of their gender, physiological and psychological nature. Also Younger age and new students have the highest risk and more potential to develop adjustment disorder as the frequency was 23 students of the 58 who are age between 18-20 years old. This maybe contributed to the sudden change in life style, new goals arises and facing new challenges. These students are mostly in the first years in the basic science that's why we can see that students in who are in the basic sciences have more and higher frequency to develop the adjustment disorder than those in the clinical years, this was just the opposite the study that was conducted in Pakistan which stated that the students in the third and fourth year had higher level of developing adjustment disorder than those who are in second year, but the first year also had a highest level of developing the disorder. Cultures and nationality could play a role but in this study there is no major deference among Gulf culture. Which was confirmed with our results that there was no relation between different nationality and adjustment disorder. According to king abdulaziz study; Medical students who pay to their institute were at higher stress than others because they could have some financial issues that contributed to their stress.

Table1: Descriptive statistics/Demographics of the participants

\begin{tabular}{|c|c|c|c|}
\hline demographical category & values & Frequency & Percent \\
\hline Age & $18-20$ & 58 & 73 \\
\hline & $21-24$ & 97 & 72 \\
\hline Academic year & basic science & 38 & 28.1 \\
\hline & clinical years & 67 & 49.6 \\
\hline Gender & male & 68 & 50.4 \\
\hline & female & 47 & 34.8 \\
\hline Nationality & Bahrain & 41 & 30.4 \\
\hline & KSA & 40 & 29.6 \\
\hline & Kuwait & 7 & 5.2 \\
\hline Marital state & others & 125 & 92.6 \\
\hline & Single & 47 & 7.4 \\
\hline & engage/married & 42 & 31.1 \\
\hline & university hostel & 42 & 3 \\
\hline & private apartment & 34.1 \\
\hline & family house & 103 & 76.3 \\
\hline & scholarship & 32 & 23.7 \\
\hline
\end{tabular}

Table 2:- analysis of the study results.

\begin{tabular}{|c|c|c|}
\hline K10 category & Frequency & Percent \\
\hline likely to be well & 51 & 37.8 \\
\hline likely to have mild mental disorder & 38 & 28.1 \\
\hline likely to have moderate mental disorder & 22 & 16.3 \\
\hline likely to have severe mental disorder & 24 & 17.8 \\
\hline No Adjustment Disorders & 89 & 65.9 \\
\hline Potential Adjustment Disorders & 46 & 34.1 \\
\hline
\end{tabular}

Table 3:- The likelihood of having adjustment disorder:

\begin{tabular}{|c|c|c|c|c|c|c|c|c|c|c|}
\hline & \multicolumn{2}{|c|}{ Gender } & \multicolumn{2}{|c|}{ Age } & \multicolumn{2}{|c|}{ Academic Stage } & \multicolumn{4}{|c|}{ Nationality } \\
\hline & $\operatorname{man}$ & Woman & $\begin{array}{l}18- \\
20\end{array}$ & $\begin{array}{c}21- \\
24\end{array}$ & $\begin{array}{c}\text { Basic } \\
\text { Sciences }\end{array}$ & $\begin{array}{c}\text { Clinical } \\
\text { Years }\end{array}$ & Bahrain & KSA & Kuwait & other \\
\hline \multirow{2}{*}{$\begin{array}{l}\text { No Adjustment } \\
\text { Disorders }\end{array}$} & 48 & 41 & 35 & 54 & 61 & 28 & 28 & 29 & 28 & 4 \\
\hline & & & & & & & & & & \\
\hline \multirow{2}{*}{$\begin{array}{c}\text { Potential } \\
\text { Adjustment } \\
\text { Disorders }\end{array}$} & 19 & 27 & 23 & 23 & 36 & 10 & 19 & 12 & 12 & 3 \\
\hline & & & & & & & & & & \\
\hline
\end{tabular}




\section{References:-}

1. Kocalevent, Rüya-Daniela, et al. "Adjustment disorders as a stress-related disorder: A longitudinal study of the associations among stress, resources, and mental health." PloS one 9.5 (2014): e97303.

2. Dyrbye LN, Massie FS Jr, Eacker A, et al. Relationship between burnout and professional conduct and attitudes among US medical students. JAMA. 2010;304(11):1173-1180

3. Dyrbye LN, Thomas MR, Shanafelt TD. Systematic review of depression, anxiety, and other indicators of psychological distress among US and Canadian medical students. Acad Med. 2006;81(4):354-373

4. Firth J. Levels and sources of stress in medical students. 1986; 1177-80.

5. de La Rosa-Rojas, Gessely, et al. "Level of stress and coping strategy in medical students compared with students of other careers." Gac Med Mex 151 (2015): 415-21.

6. Demir, Sat1, et al. "Effect of mentoring program on ways of coping with stress and locus of control for nursing students." Asian nursing research 8.4 (2014): 254-260.

7. Costa, Edméa Fontes de Oliva, et al. "Common mental disorders among medical students at Universidade Federal de Sergipe: a cross-sectional study." Revista Brasileira de Psiquiatria 32.1 (2010): 11-19.

8. Gaspersz, Roxanne, Monique HW Frings-Dresen, and Judith K. Sluiter. "Prevalence of common mental disorders among Dutch medical students and related use and need of mental health care: a cross-sectional study." (2012): 169-172.

9. Abdulghani, Hamza M., et al. "Stress and its effects on medical students: a cross-sectional study at a college of medicine in Saudi Arabia." Journal of health, population, and nutrition 29.5 (2011): 516.

10. Fares, Jawad, et al. "Stress, burnout and coping strategies in preclinical medical students." North American journal of medical sciences 8.2 (2016): 75.

11. Farahangiz, Saman, Fatemeh Mohebpour, and Alireza Salehi. "Assessment of mental health among Iranian medical students: a cross-sectional study." International journal of health sciences 10.1 (2016): 49.

12. Salam, Abdus, et al. "Stress among first and third year medical students at University Kebangsaan Malaysia." Pakistan journal of medical sciences 31.1 (2015): 169.

13. Buselli, Rodolfo, et al. "Work-related stress disorders: variability in clinical expression and pitfalls in psychiatric diagnosis." La Medicina del lavoro 107.2 (2016): 92-101.

14. Abdulghani, Hamza M., et al. "Stress and its effects on medical students: a cross-sectional study at a college of medicine in Saudi Arabia." Journal of health, population, and nutrition 29.5 (2011): 516.

15. Jensen, Charmaine, et al. "Australian university students' coping strategies and use of pharmaceutical stimulants as cognitive enhancers." Frontiers in psychology 7 (2016): 277.

16. Qamar, Khadija, Najamus Saqib Khan, and M. R. Bashir Kiani. "Factors associated with stress among medical students." J Pak Med Assoc 65.7 (2015): 753-755.

17. Loubir, Dalal Ben, et al. "Prevalence of stress in Casablanca medical students: a cross-sectional study." The Pan African Medical Journal 19 (2014).

18. El Ansari, Walid, Khalid Khalil, and Christiane Stock. "Symptoms and health complaints and their association with perceived stressors among students at nine Libyan universities." International journal of environmental research and public health 11.12 (2014): 12088-12107.

19. Bore, Miles, Brian Kelly, and Balakrishnan Nair. "Potential predictors of psychological distress and well-being in medical students: a cross-sectional pilot study." Advances in medical education and practice 7 (2016): 125.

20. Rosiek, Anna, et al. "Chronic stress and suicidal thinking among medical students." International journal of environmental research and public health 13.2 (2016): 212.

21. Wilkinson, Tim J., et al. "Identifying medical students at risk of underperformance from significant stressors." BMC medical education 16.1 (2016): 43.

22. Bassols, Ana M., et al. "First-and last-year medical students: is there a difference in the prevalence and intensity of anxiety and depressive symptoms?." Revista brasileira de psiquiatria36.3 (2014): 233-240.

23. Kessler RC, Barker PR, Colpe LJ, Epstein JF, Gfroerer JC, Hiripi E, et al. Screening for serious mental illness in the general population. Arch Gen Psychiatry. 2003 Feb;60(2):184-9.

24. G Andrews \& T Slade. Interpreting scores on the Kessler population. Australian and New Zealand Journal of Psychiatry Psychological Distress Scale (K10). Australian and New Zealand Journal of Public Health 2001, 25: 494- 497.

25. Department of health, population Research and Outcome studies BRIEF REPORTS Number : 2002-14The Kessler Psychological Distress Scale (K10)

26. Kessler, R.C., Barker, P.R., Colpe, L.J., Epstein, J.F., Gfroerer, J.C., Hiripi, E., Howes, M.J, Normand, S-L.T., Manderscheid, R.W., Walters, E.E., Zaslavsky, A.M. (2003). Screening for serious mental illness in the general population Archives of General Psychiatry. 60(2), 184-189. 